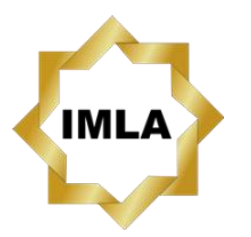

Available online:

http://journal.imla.or.id/index.php/arabi

Arabi : Journal of Arabic Studies, 6 (1), 2021, 54-67

DOI: http://dx.doi.org/10.24865/ajas.v6i1.348

\title{
BI'AH LUGHAWIYYAH ERA SOCIETY 5.0 MELALUI PENGGUNAAN MEDIA SOSIAL MAHASISWA
}

\author{
Aulia Mustika Ilmiani', Abdul Muid ${ }^{2}$ \\ ${ }^{1}$ Institut Agama Islam Negeri Palangka Raya, Indonesia \\ ${ }^{2}$ Universitas Jambi, Indonesia \\ Corresponding E-mail : aulia.mustika.ilmiani@iain-palangkaraya.ac.id
}

\begin{abstract}
Bi'ah Lughawiyyah, as the Arabic language environment is called, is a very effective means of acquiring Arabic language proficiency. In this 5.0 Era, the definition of the $b \bar{\imath}$ 'ah lughawiyyah is no longer tied to a mutually agreed time and place. Visual interaction using technology can promise unlimited access so that it can narrow space and time. Previously, bì ah lughawiyyah was often identified with a community or group that was created under a specific system or arrangement, so what about now? Amidst the massive use of social media in everyday life. This article explains the Arabic language environment in the 5.0 era in terms of students' daily activities. This study uses a descriptive qualitative approach to categorize student activities as a form of bi'ah lughawiyyah era 5.0. The subjects in this study were students of the Arabic Language Education Study Program at IAIN Palangka Raya. The data collection techniques used were observation, interview, and documentation. The results showed that bì 'ah lughawiyyah era 5.0 was dominated by social media such as Instagram, YouTube, and Facebook.
\end{abstract}

Keywords: bi'ah lughawiyyah, era of society 5.0, social media

\begin{abstract}
Abstrak
Bi'ah lughawiyyah, sebutan untuk lingkungan bahasa Arab, merupakan sarana yang sangat berpengaruh dalam perolehan kemampuan berbahasa arab. Di era 5.0 ini, definisi $b \bar{l}$ 'ah lughawiyyah tidak lagi terikat pada waktu dan tempat yang disepakati bersama. Interaksi secara visual dengan menggunakan teknologi dapat menjanjikan akses tak terbatas sehingga dapat mempersempit ruang dan waktu. Sebelumnya, $b \bar{\imath}$ ' $a h$ lughawiyyah kerapkali identik dengan sebuah komunitas atau kelompok yang diciptakan di bawah sistem atau pengaturan tertentu, lalu bagaimana dengan sekarang? Di tengah masifnya penggunaan social media dalam kehidupan sehari-hari. Artikel ini memberikan paparan terhadap $b \bar{l}$ 'ah lughawiyyah era 5.0 ditinjau dari aktivitas keseharian mahasiswa. Penelitian ini menggunakan pendekatan kualitatif deksriptif dengan tujuan mengategorikan kegiatan mahasiswa sebagai bentuk bì'ah lughawiyyah era 5.0. Subjek dalam penelitian ini adalah mahasiswa Prodi Pendidikan Bahasa Arab di IAIN Palangka Raya. Teknik pengumpulan data yang dilakukan adalah observasi, wawancara, dan dokumentasi. Hasil penelitian menunjukan bahwa $b \bar{\imath}$ 'ah lughawiyyah era 5.0 didominasi oleh penggunaan media sosial seperti: instagram, youtube dan facebook.
\end{abstract}

Kata Kunci: bi'ah lughawiyyah, era masyarakat 5.0, media sosial 


\section{Pendahuluan}

Sebagai masyarakat, manusia senantiasa berhubungan dengan lingkungan sekitarnya, pada hakikatnya lingkungan merupakan sumber daya alam untuk belajar. Lingkungan sebagai sumber belajar (dalam bahasa Arab disebut $b \bar{l}$ 'ah) dapat dikategorikan menjadi lingkungan sosial, lingkungan alam dan lingkungan buatan (Taubah, 2017). Lingkungan sosial melibatkan interaksi manusia dalam kehidupan sosial, seperti organisasi sosial, adaptasi dengan kebiasaan dan budaya. Dalam praktik pembelajaran, lingkungan sosial harus digunakan sebagai sumber belajar dari lingkungan terdekat (seperti keluarga). Lingkungan alam mencakup semua hal yang alamiah di alam, seperti kondisi geografis, iklim, udara, musim, dan makhluk hidup yang ada di sekitar. Lingkungan dapat diartikan sebagai kondisi yang diciptakan atau dibangun dengan sengaja oleh manusia untuk tujuan tertentu yang bermanfaat bagi kehidupan manusia (Darmawati, 2020). Ketiga lingkungan belajar tersebut dapat dimanfaatkan dalam proses pembelajaran di sekolah atau kampus. Salah satunya adalah pembelajaran bahasa.

Sebagaimana dua hal yang saling bergantung, bahasa dan lingkungan adalah dua sisi yang saling berdampingan. Bahasa adalah alat atau media yang digunakan untuk berinteraksi satu sama lain dan lingkungan merupakan tempat berkembangnya bahasa. Salah satu ciri bahasa adalah bahwa dalam lingkungan pribadi dan sosial, bahasa dapat tersebar tanpa adanya stagnasi (Nufus, 2020). Secara pribadi, bahasa berkembang seiring dengan usia dan pengalaman pengguna. Pada saat yang sama, dalam masyarakat, bahasa dapat dikembangkan melalui interaksi dan komunikasi antar pengguna bahasa (Sadat, 2017). Sejalan dengan perkembangan zaman, pengajar atau peserta didik menggunakan lingkungan ini untuk mempelajari bahasa kedua atau bahasa asing, yang berkaitan dengan proses pembelajaran, yang disebut lingkungan bahasa. Hedei Dulay (2015) mendefinisikan lingkungan bahasa sebagai semua konten yang didengar dan dilihat siswa terkait dengan bahasa yang mereka pelajari. Jika lingkungan kondusif untuk pembelajaran bahasa, maka pembelajaran bahasa juga akan berjalan dengan lancar.

Mengacu pada pemahaman tersebut, Hidayat (2012) menambahkan bahwa lingkungan bahasa dapat dikembangkan dari lima aspek yaitu, lingkungan visual dan visual, lingkungan pendengaran dan visual, lingkungan sosial atau interaksi belajar mengajar, dan lingkungan psikologis yang bermanfaat. Di antara kelima lingkungan tersebut, yang terpenting adalah dua pilihan pertama, yaitu lingkungan visual atau visual dan lingkungan pendengaran dan visual. Menurut penelitian Ahmad (2017), tingkat pemahaman pengetahuan melalui penglihatan mencapai $75 \%$, melalui pendengaran mencapai $13 \%$, dan melalui sentuhan dan sensasi lainnya hanya mencapai $12 \%$. Oleh karena itu, pengaruh lingkungan bahasa yang dilengkapi dengan gambar atau media visual tiga kali lebih kuat dan lebih dalam daripada bahasa ucapan atau perintah orang lain. Kebiasaan penglihatan dan pendengaran bisa dikatakan lingkungan.

Dalam banyak penelitian terdahulu disebutkan bahwa $b \bar{\imath}$ 'ah lughawiyyah merupakan sebuah wadah untuk segala jenis macam kegiatan yang dilakukan untuk mendukung peningkatan kemampuan dalam berbahasa Arab. Dalam penelitian Sa'diyah (2018) disebutkan bahwa ada dua jenis $b \bar{l}$ 'ah lughawiyyah yang diterapkan di IAIN Kudus, yaitu lingkungan formal dan lingkungan informal. Bentuk kegiatan $b \bar{\imath}$ 'ah lughawiyyah dalam lingkungan resmi yaitu pendidikan regular di kelas dengan penggunaan bahasa Arab sebagai bahasa dasar dalam proses pendidikan, menyediakan kurikulum pembelajaran bahasa Arab yang tepat dan juga mengadakan symposium ilmiah Arab setiap tahunnya. Adapun kegiatan $b \bar{l}$ 'ah lughawiyyah dalam lingkungan informal yaitu adanya departemen bahasa di setiap kelompok/panggung, mengelola majalah dinding berbahasa Arab, membentuk persatuan mahasiswa bahasa Arab dan juga menyelenggarakan Festival Bahasa Arab setiap tahun (Sa'diyah, 2018).

Kegiatan-kegiatan yang diterapkan dalam $b \bar{\imath}$ 'ah lughawiyyah dijelaskan terperinci, sebagaimana temuan Aflisia dan Harahap (2019), hasil penelitiannya menyebutkan bahwa kegiatan kegiatan yang berlangsung di IAIN Curup sebagai bentuk lingkungan berbahasa adalah Muhādharah (Pidato), Istinbath, Drama Bahasa Arab, Puisi Bahasa Arab, Master of Ceremony 


\section{Arabi : Journal of Arabic Studies}

(MC) Bahasa Arab dan Muhādatsah (Aflisia \& Harahap, 2019). Kegiatan ini hampir serupa dengan hasil penelitiannya Wahyuningsih dan Fauzi (2019), dalam tulisannya disebutkan bahwa penerapan $b \bar{l}$ 'ah lughawiyyah dalam kegiatan berbahasa adalah Tutorial Bahasa, Pidato (Muhadharah), Muhādastah, Language Time, Drilling, Mahrajān Lughawi (Wahyuningsih \& Fauzi, 2019). Nufus (2020) dalam penelitiannya menambahkan bahwa $b{ }^{\prime}$ 'ah lughawiyyah diterapkan dengan menjalankan pembiasaan menggunakan bahasa Arab pada hari khusus berbahasa, melakukan kegiatan ilqa al-mufradät, berlatih muhädastah, berlatih imlä' muwajjah dan mengadakan mahkamah lughah (Nufus, 2020).

Idealnya $b \bar{l}$ 'ah lughawiyyah adalah suatu kondisi yang memungkinkan seseorang dengan sengaja mengeksplorasi kemampuan bahasanya, baik lewat pendengaran, pengucapan, maupun tulisan. Hal ini bisa terbentuk oleh kegiatan berkelompok secara massal dengan cara membuat suatu grup atau komunitas yang diatur oleh sebuah sistem. Namun faktanya kondisi ini, belum dapat dimanfaatkan secara maksimal dikarenakan beberapa kendala, di antaranya adalah minimnya wadah atau tempat yang dapat memfasilitasi terbentuknya lingkungan bahasa Arab secara formal maupun non-formal, khususnya di daerah Palangka Raya dan rendahnya minat pembiasaan berbahasa arab secara komunikatif dalam kegiatan sehari hari yang disebabkan oleh rasa tidak percaya diri. Kebanyakan mahasiswa beranggapan bahwa sangat sulit memulai untuk berinteraksi menggunakan bahasa Arab apabila tidak memiliki lawan bicara. Melihat permasalahan ini, maka penggunaan media sosial, sebagai bagian dari perkembangan teknologi di dunia pendidikan kiranya dapat dimanfaatkan sebagai lingkungan bahasa. Hal ini didasari oleh masifnya penggunaan media sosial dalam kehidupan sehari-hari, sebagaimana observasi awal peneliti diketahui bahwa mahasiswa dapat memperoleh pembelajaran bahasa Arab sejalan dengan penggunaan media social tersebut. Kondisi ini serupa dengan pernyataan Nastiti dan Abdu, dalam artikelnya disebutkan bahwa pada era Society 5.0 ini, proses pembelajaran dapat dilakukan dengan kelas on line melalui media social (Nastiti \& Abdu, 2020).

Era Society 5.0 dapat didefinisikan sebagai masyarakat yang cerdas (Suwandi, 2020), yang dapat mengintegrasikan dunia fisik dan dunia maya dengan kemampuan beradaptasi, kelincahan, mobilitas dan daya tanggap. Konsep yang diusung dalam era Society 5.0 adalah kehidupan berpusat pada teknologi (Nastiti \& Abdu, 2020). Sejalan dengan itu, pendidikan dalam konsep era sosial 5.0 harus mengutamakan pengembangan kreativitas yang menggunakan teknologi untuk meningkatkan kualitas pembelajaran. Baik pendidik maupun peserta didik sedang menghadapi era digital dengan karakteristik khusus. Lestiani mengatakan bahwa generasi yang lahir di era digital ini adalah digital native, artinya sejak lahir sudah mengenal berbagai perangkat digital, seperti komputer, gadget, video game, pemutar musik digital, kamera dan peralatan era digital (Lestiyani, 2020; Liu et al., 2016). Internet dan komputer merupakan alat yang memfasilitasi proses pengajaran. Kemunculan internet dan kecepatan mesin pencari melahirkan gerakan literasi digital. Mencari teori, konsep, praktik dan segala jenis ilmu melalui internet sangatlah mudah dan cepat, perkembangan teknologi dengan cepat merambah ke dalam aktivitas sosial manusia, bahkan proses pembelajaran dapat diselesaikan melalui kursus online melalui media sosial. Media sosial on line digunakan untuk berbagi, berpartisipasi, dan membuat konten di blog atau jejaring social (Weinstein, 2018). Variasi media sosial memang selalu berkembang, tetapi di Indonesia hanya beberapa media sosial yang banyak digunakan seperti Facebook, Twitter, Instagram, WhatsApp, Youtube dan Line (Yanuarti \& Sari, 2019). Aplikasi media sosial ini merupakan makna perkembangan teknologi yang mengarah pada aktivitas sosial (Kolokytha, et.al., 2015; Moghavvemi et al., 2018).

Media media tersebut memberikan kemudahan kepada orang melakukan interaksi sosial tanpa terhalang oleh ruang dan waktu. Beberapa penelitian di bawah ini membuktikan keefektifan penggunaan media sosial (Fardischa, 2020; Kamhar \& Lestari, 2019; Sahlström et al., 2019; Salehudin, 2020; Yanuarti \& Sari, 2019). Terkhusus penelitian mengenai penggunaan media sosial dalam pembelajaran Bahasa Arab adalah sebagai berikut; pertama, penelitian yang dilakukan oleh 
Ilmiani dkk (2020) dalam penelitiannya disebutkan bahwa media whatsapp merupakan salah satu media sosial popular yang dimanfaatkan dalam pembelajaran bahasa Arab. Kedua, penelitian yang dilakukan oleh Linur dan Mubarak (2020) \& Mubarak et al. (2020a), tentang penggunaan facebook yang terbukti efektif untuk meningkatkan kemampuan menulis pembelajaran bahasa Arab. Ketiga, penelitian yang dilakukan oleh Syukriya (2019) mengenai instagram sebagai media alternative dalam meningkatkan kemampuan berbahasa Arab. Selain itu, tak dapat dipungkiri, para peserta didik cenderung lebih lama menghabiskan waktunya untuk berinteraksi dengan gadgetnya dibandingkan dengan interaksi sosial secara nyata. Mereka lebih tertarik dengan aktivitas sosial di dunia maya, apalagi dalam prinsip pembelajaran era Society 5.0, peserta didik dapat bebas memilih dan memiliki otonomi penuh dalam menciptakan pembelajaran yang aktif, proaktif dan menyenangkan bagi dirinya sendiri (F. Ahmadi \& Ibda, 2019; Arjunaita, 2020).

Dari kondisi ini, diketahui bahwa penggunaan media sosial merupakan salah satu perkembangan teknologi pembelajaran yang dapat dikatakan sebagai wadah baru bagi lingkungan bahasa. Dalam kaitannya dengan pembelajaran bahasa asing, lingkungan bahasa merupakan salah satu faktor yang sangat berpengaruh dalam pembelajaran bahasa. Sebagaimana yang disebutkan oleh Purba (2013), faktor lingkungan didasari oleh teori behavioristik (Griffiths, 2019), dalam tulisannya disebutkan bahwa lingkungan bahasa sangat mempengaruhi proses pembelajaran bahasa.

Secara sederhana lingkungan bahasa terbagi menjadi dua jenis: pertama, formal (formal environment) dan yang kedua adalah informal (informal environment). Lingkungan akan disebut formal, manakala lingkungan tersebut terjadi dalam forum resmi, seperti pembelajaran bahasa yang terjadi di dalam kelas atau kursus. Sedangkan lingkungan akan disebut informal, ketika lingkungan tersebut terjadi secara alami, memberikan komunikasi secara alami. Ini bisa juga dipahami bahwa lingkungan tersebut tidak hanya berkutat di dalam kelas yang monoton, tetapi mencangkup lingkungan secara keseluruhan. Oleh Karena itu lingkungan informal ini memberikan porsi lebih banyak wacana bahasa daripada sistem bahasa.

Berdasarkan hasil wawancara awal, diketahui bahwa menurut mahasiswa Prodi PBA IAIN Palangka Raya, mereka dapat mempelajari bahasa Arab secara lebih intens lewat penggunaan media sosial dalam kegiatan sehari-hari. Hal ini menarik untuk ditelaah lebih lanjut. Berangkat dari permasalahan inilah, maka penelitian ini bertujuan untuk mendeksripsikan $b \bar{\imath}$ 'ah lughawiyyah ditinjau dari aktivitas sehari-hari mahasiswa Prodi Pendidikan Bahasa Arab di IAIN Palangka Raya, ditengah merebaknya penggunaan media sosial dalam segala aspek, termasuk pada aspek pembelajaran bahasa Arab. Pembahasan ini dirasa perlu untuk ditelaah lebih lanjut, karena memiliki nilai kebaharuan dalam bidang $b \bar{l}$ 'ah lughawiyyah, peneliti akan menelaah lebih dalam, apa saja media sosial yang digunakan oleh mahasiswa Prodi PBA IAIN Palangka Raya dan bagaimana penggunaan sosial media dapat dikatakan sebagai $b \bar{l}$ 'ah lughawiyyah.

Adapun pertanyaan penelitian dalam artikel ini adalah apa saja jenis media sosial yang digunakan oleh mahasiswa Prodi PBA dan bagaimana deksripsi $b \bar{\imath}$ 'ah lughawiyyah era Society 5.0 ditinjau dari kegiatan sehari-sehari mahasiswa Prodi PBA di IAIN Palangka Raya.

\section{Metode Penelitian}

Penelitian ini merupakan penelitian lapangan (field research) dengan metode kualitatif deksriptif. Waktu pelaksanaan penelitian ini terhitung dari bulan Maret 2020 hingga bulan Januari 2021, di mana seluruh mahasiswa IAIN Palangka Raya mengikuti pembelajaran online atau jarak jauh. Lokasi penelitian ini adalah Prodi PBA IAIN Palangka Raya. Tujuan dari penelitian ini adalah $b \bar{l}$ 'ah lughawiyyah ditinjau dari kegiatan sehari-hari mahasiswa Prodi PBA. Di lingkungan IAIN Palangka Raya, informan yang membantu dalam pelaksanaan penelitian ini adalah dosen dan tenaga pendidik pada Prodi PBA di IAIN Palangka Raya. Sumber data penelitian ini dibedakan menjadi dua jenis, yaitu data primer dan data sekunder. Data primer diperoleh melalui observasi, wawancara dan dokumentasi kepada partisipan yang meliputi mahasiswa Prodi PBA IAIN 


\section{Arabi : Journal of Arabic Studies}

Palangka Raya seluruh angkatan yang berjumlah 145 orang. Sedangkan data sekunder diperoleh dari buku, jurnal dan sumber lain yang dianggap relevan dengan penelitian.

Dalam penelitian ini digambarkan kegiatan-kegiatan yang dilakukan oleh mahasiswa Prodi PBA sebagai bentuk kegiatan lingkungan berbahasa. Fokus penelitian ini adalah $b \bar{l}$ 'ah lughawiyyah era Society 5.0 dilihat dari aktivitas keseharian mahasiswa Prodi PBA di IAIN Palangka Raya. Untuk mendapatkan data yang diperlukan dalam penelitian ini, penulis menggunakan teknik pengumpulan data dengan cara: pertama, mewawancarai mahasiswa Prodi PBA IAIN Palangka Raya, dosen, dan teman sejawat sebagai sumber primer dan sumber sekunder. Kedua, melakukan observasi pada proses berlangsungnya kegiatan sehari-hari mahasiswa Prodi PBA dan proses pembelajaran Bahasa Arab yang dilakukan. Observasi dilakukan secara berkala dengan tenggang waktu yang berbeda-beda. Ketiga, pengumpulan dokumentasi. Adapun dokumentasi yang dikumpulkan berupa foto kegiatan, referensi, Ppt. dan bahan yang digunakan dalam pembelajaran.

Teknik analisis data yang digunakan mulai dari reduksi data, display data dan verifikasi (penarikan kesimpulan). Untuk uji keabsahan data dilakukan dengan teknik triangulasi, yaitu triangulasi sumber dan teknik pengumpulan data.

\section{Hasil Penelitian dan Pembahasan}

Berdasarkan hasil analisis deksriptif yang peneliti lakukan selama 10 bulan, dengan melakukan wawancara terstruktur menggunakan google form pada mahasiswa Prodi Pendidikan Bahasa Arab di IAIN Palangka Raya yang berjumlah 145 orang, dapat diketahui bahwa persepsi mahasiswa mengenai $b \bar{\imath}$ 'ah lughawiyyah bahasa Arab didominasi oleh penggunaan media sosial dengan presentase $80 \%$. Data tersebut disusun dalam tabel di bawah ini:

\section{Bi'ah Lughawiyyah \\ (Lingkungan Bahasa Arab Era Society 5.0)}

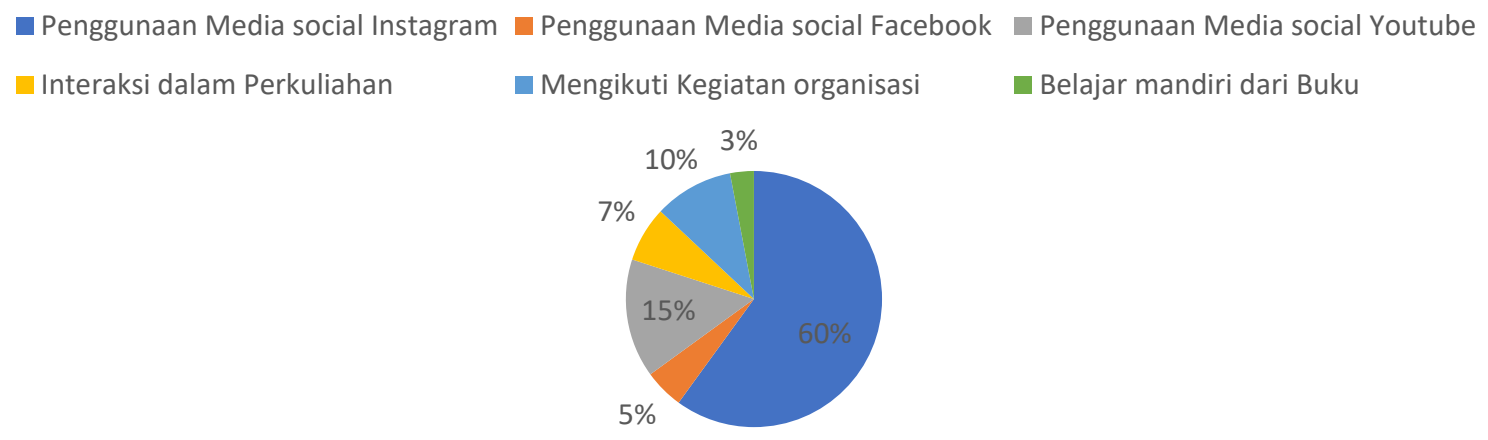

Dari tabel di atas dapat diketahui bahwa $80 \%$ pertama persepsi mahasiswa mengenai $b \bar{l}$ 'ah lughawiyyah yang mereka dapatkan diperoleh melalui kegiatan menggunakan media sosial. Pada urutan pertama penggunaan media sosial Instagram, pada urutan kedua media sosial facebook dan pada urutan ketiga media sosial youtube. Sementara $20 \%$ yang tersisa, mahasiswa mendapatkan bi'ah lughawiyyah dari interaksi perkuliahan, kegiatan organisasi dan belajar mandiri.

Ada beberapa factor yang menyebabkan bi'ah lughawiyyah menurut mahasiswa Prodi PBA di IAIN Palangka Raya didominasi oleh penggunaan media sosial: Pertama, mahasiswa Prodi PBA merupakan mahasiswa yang berumur kisaran 17-21 tahun. Diusia ini, para mahasiswa dilahirkan bersamaan dengan tumbuh kembangnya digitalisasi dalam kehidupan mereka, mereka yang lahir ditahun 2000-an ke atas hingga kini disebut dengan istilah era milenial. Sebagaimana pernyataan 
DeVaney (2015), generasi milenial lahir antara 1980 hingga 2000. Peristiwa awal dalam kehidupan milenial adalah globalisme. Pada era milenial ini, gaya belajar mahasiswa dipengaruhi dengan lajunya perkembangan media sosial. Penggunaan internet dan gadjet merupakan sebuah kebutuhan yang tak terelakan. Gaya belajar mereka pun mengalami pergeseran. Mahasiswa dapat mengupgrade keilmuan mereka dengan aktif menggunakan media sosial. Pernyataan ini didukung oleh hasil penelitian (Akçayır et al., 2016). Hasil statistik menunjukan bahwa mahasiswa mendapatkan pengetahuan dan pengalaman baru setelah menggunakan teknologi seperti komputer, tablet PC, dan internet.

Kedua, menggunakan media sosial tidak seperti sedang belajar. Pada umumnya media sosial merupakan sarana berkomunikasi yang dapat dilakukan di mana saja, sehingga dapat memudahkan penggunanya berinteraksi satu sama lain tanpa batasan ruang dan waktu. Namun dewasa ini, media sosial berkembang menjadi ajang popularitas bagi anak muda, bahkan orang dewasa lainnya. Menggunakan media sosial merupakan keharusan, tidak hanya agar dapat saling terhubung namun juga sebagai strata popularitas agar tidak ketinggalan zaman. Penggunaan media sosial dianggap sebagai kebutuhan bagi semua orang. (Mao, 2014) menyebutkan dalam artikelnya bahwa orang-orang bergantung pada media sosial dalam kehidupan sehari-hari mereka untuk rekreasi dan koneksi sosial. Berdasarkan ini, pemanfaatan media sosial pun menjadi jauh lebih beragam tergantung kondisi dan situasi pengguna. Bagi kalangan mahasiswa penggunaan media sosial, mempunyai fungsi beragam. Sebagai sarana berkomunikasi dan perkenalan antar teman kuliah, sebagai sarana untuk menghimpun sebuah organisasi, sebagai wadah untuk komunitas, sebagai sumber informasi, dan tentunya sebagai media pembelajaran. Media sosial sangat memungkinkan digunakan sebagai media pembelajaran. Karena hampir semua mahasiswa pada Prodi PBA IAIN Palangka Raya memiliki media sosial. Tidak hanya satu, bahkan banyak mahasiswa Prodi PBA IAIN Palangka Raya mengaku bahwa memiliki beberapa media sosial sekaligus, seperti: facebook, instagram, youtube, twitter, path, telegram dll.

Pada hasil wawancara dengan mahasiswa Prodi PBA IAIN Palangka Raya, yang berkaitan dengan lingkungan pembelajaran bahasa. Alasan mereka menggunakan media sosial adalah untuk memanfaatkan media sosial mereka sebagai sumber belajar mandiri. Khususnya pada pembelajaran bahasa Arab. Bagi mahasiswa Prodi PBA yang berlatar belakang pendidikan umum menyatakan bahwa pengetahuan mereka sangat minim sekali tentang pembelajaran bahasa Arab di sekolah sebelumnya. Dan media sosial dapat digunakan sebagai sumber belajar bahasa Arab yang cepat, ringkas, mudah di akses di mana saja dan tentunya gratis. Mereka dapat menemukan informasi sederhana terkait kosa kata bahasa Arab, percakapan sehari-hari dalam bahasa Arab, kaidah-kaidah dalam bahasa Arab dan juga informasi lainnya. Mereka menyebutkan media sosial dapat digunakan sebagai supplement atau tambahan referensi sumber belajar selain dari yang mereka dapatkan pada pembelajaran diperkuliahan. Dan yang menarik adalah pendapat mereka dalam penggunaan media sosial sebagai $b \bar{\imath}$ 'ah lughawiyyah ini. Mereka mengungkapkan bahwa penggunaan media sosial sebagai lingkungan pembelajaran bahasa, sama sekali tidak membebani, atau membuat mereka merasa sedang belajar, tidak ada batasan waktu, tidak ada aturan penggunaan, tidak ada keharusan untuk mengadopsi pembelajaran yang mana, semua bebas dapat dilakukan murni karena ketertarikan pribadi atau masing-masing individual. Mereka tidak perlu jauh-jauh keluar pulau atau kota, untuk mengikuti mendapatkan $b \bar{l}$ 'ah lughawiyyah seperti pada kursus bahasa Arab di Pare misalnya. Mereka cukup dapat berpartisipasi secara online, mengikuti berbagai kegiatan pembelajaran bahasa di rumah masing-masing,

Ketiga, perkuliahan pada Prodi PBA IAIN Palangka Raya banyak memanfaatkan media sosial. Pada hasil wawancara peneliti dengan mahasiswa Prodi PBA IAIN Palangka Raya, dosen Prodi PBA banyak memanfaatkan media sosial sebagai pendukung aktivitas pembelajaran mereka, bahkan juga digunakan sebagai media pembelajaran. Pada sebagian besar aktivitas pembelajaran, dalam perkuliahan mereka menggunakan media whatsapp (Ilmiani, Hamidah, et al., 2020) (Ilmiani, 


\section{Arabi : Journal of Arabic Studies}

Marsiah, et al., 2020; Mubarak et al., 2020b) (Ilmiani, Ahmadi, et al., 2020) selain itu media youtube (A. Ahmadi \& Ilmiani, 2020) juga digunakan sebagai media pembelajaran karena dianggap lebih mudah diakses, apabila pembelajaran membutuhkan video, jadi sebagian besar dosen Program Studi Pendidikan Bahasa Arab memiliki akun kanal Youtube pribadi, (https://www.youtube.com/channel/UCW448IDWdp72yaFTQ45eCmw) yang konten videonya merupakan penjelasan-penjelasan perkuliahan. Media sosial lain yang biasa digunakan sebagai media pembelajaran adalah instagram dan facebook. Dalam beberapa kesempatan dosen meminta mahasiswanya mencari referensi atau sumber belajar tambahan dari beberapa akun terpercaya dan valid dari segi keabsahan pembelajarannya.

Keempat, kondisi pandemic yang mendukung. Pandemi Covid-19 yang muncul pada pertengahan Maret 2020 lalu, sontak membuat seluruh aktivitas perkuliahan dialihkan menjadi perkuliahan jarak jauh. Kondisi ini membuat seluruh orang tak terkecuali mahasiswa lebih banyak menghabiskan waktu dirumah. Selain itu seluruh aktivitas perkuliahan juga bergantung dengan penggunaan smartphone atau gadget, belum lagi tugas-tugas perkuliahan yang kerap memanfaatkan media sosial, oleh sebab itu secara tidak langsung mahasiswa mempunyai kesempatan lebih banyak dalam mengakses dan menggunakan media sosial mereka. Keikutsertaan mahasiswa Prodi PBA dalam workshop-workshop yang biasa ditampilkan secara langsung lewat youtube, dan juga sebagian besar mahasiswa Prodi PBA merupakan pegiat organisasi yang aktif baik di media sosial maupun didunia nyata.

Kelima, penggunaan media sosial lebih mudah terlacak dan meninggalkan rekam digital. Dijumpai dalam wawancara secara mendalam bersama mahasiswa Prodi PBA, ia menjelaskan bahwa, perkuliahan selama masa pandemi, memang membuat mereka menjadi lebih akrab dengan kondisi di mana pembelajaran bahasa Arab menjadi lebih sering menggunakan media sosial. Tugas yang diberikan dosen Prodi PBA, acapkali juga menggunakan media sosial, bahkan untuk sarana pengumpulan tugas. Pada beberapa mata kuliah dalam pembelajaran bahasa Arab di Prodi PBA IAIN Palangka Raya. Tugas yang diberikan merupakan tugas yang berbasis proyek atau tugas yang menghasilkan produk. Oleh sebab itu, sebagaimana hasil wawancara peneliti beserta observasi selama beberapa bulan, hasil penelitian yang didapatkan adalah dosen meminta mahasiswa mengumpulkan tugas mereka berbentuk video, agar kemudian bisa diunggah ke media sosial, salah sat unya adalah youtube, selain itu ada juga yang meminta mahasiswanya untuk mengunggah pada tampilan instagram atau facebook. Hal ini bertujuan agar tugas tersebut mempunyai rekam digital dan dapat diakses kembali oleh adik tingkat dan teman sejawat, namun sebelum mereka melakukan pengunggahan, terlebih dulu wajib diroscek oleh dosen yang mengampu mata kuliah tersebut, agar informasi yang disebarkan tidak salah ataupun keliru.

Adapun media-media Sosial yang dominan digunakan oleh mahasiswa Prodi PBA IAIN Palangka Raya adalah instagram, youtube dan facebook. Tiga media sosial ini merupakan $b \vec{\imath}$ 'ah lughawiyyah yang paling dirasakan mendominasi keseharian mereka terkait hubungannya dengan pembelajaran bahasa Arab. Peneliti akan menjelaskan satu persatu, media sosial yang digunakan sebagai $b \bar{l}$ 'ah lughawiyyah di era Society 5.0 dalam perspektif mahasiswa Prodi PBA IAIN Palangka Raya; Pertama, Instagram. Media sosial instagram merupakan salah satu media sosial yang sedang hits di kalangan remaja, bahkan orang dewasa, tak terkecuali mahasiswa. Media sosial yang menyuguhkan banyak fitur dengan beragam fungsi ini, salah satunya memungkinkan para pengguna untuk membagikan foto atau video kepada orang yang mengikutinya di media sosial. Para mahasiswa Prodi PBA pada umumnya menggunakan media Instagram ini untuk mengikuti (follow) akun-akun official atau akun khusus yang membahas terkait pembelajaran bahasa Arab. Pembelajaran bahasa Arab yang dimaksud beragam, seperti kosa kata bahasa Arab, percakapan bahasa Arab, kaidah dalam pembelajaran bahasa Arab seperti nahwu dan sharaf. Hal ini mereka lakukan selain untuk lebih mengenal bahasa Arab itu sendiri namun juga untuk memperkaya keilmuan mereka terkait pembelajaran bahasa Arab dengan mandiri, sesuai yang mereka butuhkan. 
Sebagaimana diketahui bahwa materi pembelajaran bahasa Arab yang disuguhkan selama perkuliahan, tidak serta merta materi dasar, sehingga para pelajar bahasa Arab khususnya pemula wajib memperkaya sendiri pengetahuan dasar mereka tentang bahasa Arab. Mahasiswa Prodi PBA banyak yang berlatar pendidikan sekolah umum, di mana tentunya pengetahuan dasar tentang bahasa Arab sangat sedikit mereka temukan pada sekolah sebelumnya. Oleh sebab itu, merupakan suatu keharusan bagi mereka pribadi untuk menambah sumber belajar mereka, caranya adalah mendekatkan kegiatan sehari-hari mereka dengan aktivitas terkait pembelajaran bahasa Arab. Dengan mengikuti (follow) Instagram yang memberikan fasilitas pengetahuan tentang bahasa Arab secara gratis, maka dengan demikian mereka sedang membiasakan diri terhadap lingkungan bahasa, karena mereka mengamati, mengaplikasikan dan cenderung mengikuti apa saja yang disarankan oleh akun tersebut.

Kedua, youtube. Media sosial youtube adalah media sosial yang menyuguhkan beragam video dengan durasi lebih lama dibandingkan instagram. Adapun konten yang tersedia beragam, mulai dari acara TV, music, film, pengetahuan, hiburan, bahkan kegiatan sehari-hari pemilik akunnya. Dewasa ini, semakin banyak pula yang memanfaatkan media sosial youtube untuk fasilitas pendidikan. Tidak terkecuali pembelajaran bahasa Arab. Hanya dengan memasukan kata kunci yang tepat, (misalnya: Pembelajaran Bahasa Arab) maka akan muncul beragam video pembelajaran bahasa Arab. Oleh karenanya sebagaimana hasil penelitian yang dilakukan, menurut perspektif mahasiswa Prodi PBA, maka diketahui bahwa media sosial youtube dapat digunakan mahasiswa sebagai $b \bar{\imath}$ 'ah lughawiyyah yang membantu mahasiswa dalam pembelajaran bahasa Arab. Mahasiswa dapat menonton native speaker bahasa Arab secara langsung, dan dapat memilih konten bahasa Arab mana yang lebih mudah ia pelajari. Mereka juga dapat belajar di mana saja, kapan saja, dan mengakses sebanyak yang mereka mau. Dan juga dengan durasi waktu yang lebih panjang, dibandingkan media sosial yang lain, mahasiswa mendapatkan penjelasan utuh, sekaligus tanpa terpotong oleh durasi yang waktu yang ditentukan. Dengan kemudahan seperti inilah, mereka menganggap bahwa media sosial youtube cukup mengambil peran, sebagai $b \bar{\imath}$ 'ah lughawiyyah yang mereka rasakan.

Ketiga, media sosial facebook. Dibandingkan dua media social sebelumnya, media sosial facebook merupakan aplikasi yang lebih dulu populer di zamannya. Hampir semua kalangan memiliki akun facebook. Akun facebook ini, dapat digunakan oleh orang tua bahkan anak-anak. Mereka menggunakan akun facebook sebagai sarana mencari teman atau sekadar bergabung pada suatu komunitas atau grup. Sebagaimana hasil penelitian yang dilakukan, maka diketahui bahwa menurut mahasiswa Prodi PBA IAIN Palangka Raya, media sosial facebook merupakan salah satu $b \bar{l}$ 'ah lughawiyyah yang dapat mendorong mahasiswa dalam pembelajaran bahasa arab. Dalam media sosial facebook, terdapat fitur komunitas atau grup yang dapat dijadikan sebagai sebuah laman yang dikhususkan untuk perkumpulan banyak orang. Beragam laman ini berisi informasi beragam, tidak terkecuali komunitas tentang pembelajar bahasa Arab. Tanpa harus mengikuti satu sama lain (sebagaimana pada media sosial Instagram) atau berteman (istilah yang digunakan dalam media sosial facebook) maka satu sama lain dapat tergabung dalam sebuah grup. Dari grup inilah, banyak informasi yang bisa kita dapatkan, misalnya tentang pembelajaran bahasa Arab. Pembelajaran bahasa Arab juga sangat banyak, tersedia dengan berbagai pilihan, yang ada di dalam negeri atau diluar negeri. Semua dapat terjangkau hanya dengan menggunakan media sosial. Bagi mahasiswa, dengan menggunakan media sosial facebook mereka dapat mengambil manfaat dan menjadikannya sebagai $b \bar{l}$ 'ah lughawiyyah.

Sementara itu tiga pilihan terbawah, mengenai $b \bar{t}$ 'ah lughawiyyah di era Society 5.0 menurut mahasiswa Prodi PBA IAIN Palangka Raya adalah interaksi dalam perkuliahan, mengikuti kegiatan organisasi, dan belajar mandiri dari buku. Peneliti membahas ini satu persatu sebagaimana hasil penelitian. Yang Pertama, interaksi dalam perkuliahan. Menurut mahasiswa Prodi PBA interaksi dalam perkuliahan merupakan salah satu aktivitas terstuktur yang dilakukan 


\section{Arabi : Journal of Arabic Studies}

oleh mahasiswa Prodi PBA sebagai bagian bi'ah lughawiyyah yang mereka rasakan dalam kegiatan sehari-hari. Interaksi yang dimaksud yaitu seperti proses perkuliahan yang berlangsung. Dalam beberapa mata kuliah tertentu, dosen Prodi PBA memang menggunakan bahasa Arab selama pembelajaran berlangsung. Dengan demikian, dari aktivitas tersebut mahasiswa Prodi PBA dapat mengenal kosa kata bahasa Arab dasar yang digunakan dalam percakapan. Seperti saat sedang membuka diskusi, memulai pelajaran, menjelaskan pelajaran, memberikan pertanyaan, mengomentari dan terakhir meangakhiri pembelajaran. Selain itu, mahasiswa juga dapat mengetahui ungkapan-ungkapan bahasa Arab yang digunakan ketika menjadi presenter makalah, menjadi moderator dan menjadi penanggap. Pada beberapa kesempatan juga ketika berkomunikasi dengan dosen Prodi PBA di kantor, maka diwajibkan menggunakan bahasa Arab. Oleh sebab itu, mahasiswa Prodi PBA membiasakan diri mengetahui percakapan bahasa Arab dasar, yang digunakan dalam kehidupan sehari-hari.

Kedua, mengikuti kegiatan organisasi. Berdasarkan hasil wawancara yang peneliti lakukan pada mahasiswa Prodi PBA, ditinjau juga dari hasil pengamatan dan dokumentasi yang dikumpulkan maka diketahui bahwa ada beberapa kegiatan organisasi rutin yang mereka ikuti, terkait pembelajaran bahasa Arab. Beberapa organisasi yang dimanfaatkan sebagai $b \bar{l}$ 'ah lughawiyyah mahasiswa Prodi PBA adalah sebagai berikut: 1) HMPS PBA; pada awalnya HMPS PBA hanya merupakan wadah organisasi terkait pengurus himpunan mahasiswa Prodi PBA saja, namun dari organisasi inilah diprogramkan beberapa kegiatan yang menjadi wadah untuk para mahasiswa saling berbagi pengetahuan, pembelajaran, dan pengalaman. 2) FILAR; Firqah alLughah al-'Arabiyyah merupakan salah satu organisasi yang menjadi wadah para pegiat bahasa Arab, organisasi ini tidak hanya beranggota dari mahasiswa Prodi PBA saja namun dapat diikuti oleh mahasiswa dari Prodi atau jurusan lain. Dalam kegiatannya program yang dilaksanakan bertujuan sebagai sarana pembelajaran bahasa Arab, baik dari segi kemampuan berbahasa dan kemampuan pada unsur bahasa Arab lainnya. Kegiatan ini dilaksanakan dua kali seminggu, bertempat di sekitar wilayah outdoor Kampus IAIN Palangka Raya. Adapun kegiatan yang dilaksanakan beragam, seperti latihan muhadatsah, berbagi mufradat baru, latihan pidato, MC, puisi dan juga drama berbahasa Arab, tak lupa juga permainan-permainan bahasa unt uk menambah daya ingat dan konsentrasi mahasiswa Prodi PBA 3) Tutor Sebaya; kegiatan ini merupakan salah satu kegiatan HMPS PBA, yang berfokus pada pembinaan mahasiswa baru prodi PBA, adapun yang menjadi tutor nya adalah mahasiswa yang menjadi kaka tingkat untuk mahasiswa baru ini. Hal-hal yang dilakukan dalam kegiatan ini beragam, di antaranya adalah mendampingi mahasiswa baru Prodi PBA dalam kegiatan pembelajaran, khususnya apabila mengalami kesulitan. Selain itu dalam kegiatan Tutor Sebaya, para tutor juga memberikan pembelajaran bahasa Arab berupa kosakata, ungkapan-ungkapan harian dalam bahasa Arab serta kaidah dalam pembelajaran bahasa Arab. Pembelajaran ini diadakan secara terjadwal dan dilakukan secara off line maupun on line. 4) Pengabdian Mahasiswa Prodi PBA; Kegiatan pengabdian mahasiswa Prodi PBA merupakan salah satu kegiatan HMPS PBA, yang berfokus pada kegiatan luaran mahasiswa Prodi PBA, kegiatan pengabdian ini berlokasi di Pondok Pesantren atau panti asuhan sekitar wilayah kampus IAIN Palangka Raya. Pada kegiatan ini, mahasiswa Prodi PBA memberikan pembelajaran bahasa Arab kepada anak-anak usia madrasah hingga Aliyah. Seperti latihan membaca teks bahasa Arab, menulis dan berbicara dalam bahasa Arab. Mahasiswa Prodi PBA juga memberikan pelatihan dalam pidato bahasa Arab, MC dan juga drama berbahasa Arab.

Ketiga, Belajar mandiri dari buku. Dari hasil penelitian, pilihan ini merupakan pilihan paling sedikit dalam perspektif mahasiswa terkait $b \bar{l}$ 'ah lughawiyyah yang mereka rasakan dalam kegiatan sehari-hari. Alasannya adalah belajar mandiri lewat buku butuh minat dan tekad bagi masing masing individu, dan pembelajaran bahasa juga lebih efektif apabila dilakukan secara berkelompok, atau setidaknya ada lawan bicara. Namun menurut perspektif mahasiswa yang melakukan aktivitas belajar mandiri lewat buku sebagai suatu wadah $b \bar{l}$ 'ah lughawiyyah, mereka 
dapat mempelajari kosa kata yang tidak mereka ketahui, mereka dapat mempraktikan percakapan sederhana secara mandiri, baru kemudian mengaplikasikan bersama dengan orang lain.

Sebagaimana hasil penelitian pada mahasiswa Prodi PBA di IAIN Palangka Raya, diketahui bahwa $b \bar{l}$ 'ah lughawiyyah era Society 5.0 terbagi pada enam bagian yaitu penggunaan media sosial instagram, penggunaan media sosial youtube, penggunaan media sosial facebook, interaksi dalam perkuliahan, mengikuti kegiatan organisasi dan belajar mandiri dari buku. Dilihat dari aktivitas yang dilakukan oleh mahasiswa Prodi PBA, bì'ah lughawiyyah era Society dapat dikategorikan menjadi dua jenis yaitu lingkungan bahasa formal dan lingkungan bahasa informal. Lingkungan akan disebut formal, manakala lingkungan tersebut terjadi dalam forum resmi, seperti pembelajaran bahasa yang terjadi di dalam kelas ataupun kursus. Lingkungan ini memberikan kepada pelajar berupa sistem bahasa (pengetahuan unsur-unsur bahasa) atau wacana bahasa (keterampilan berbahasa), Sedangkan lingkungan akan disebut informal, ketika lingkungan tersebut terjadi secara alami, memberikan komunikasi secara alami. Ini bisa juga dipahami, bahwa lingkungan tersebut tidak hanya berkutat di dalam kelas yang monoton, tetapi mencangkup lingkungan secara keseluruhan (Salim, 2013). Mengacu dari pernyataan ini, maka $b \bar{l}$ 'ah lughawiyyah menurut mahasiswa Prodi PBA IAIN Palangka Raya yang mencakup lingkungan bahasa formal adalah interaksi dalam perkuliahan, sedangkan yang mencakup lingkungan bahasa informal adalah mengikuti kegiatan organisasi, belajar mandiri dari buku dan penggunaan media sosial.

Dilihat dari hasil presentase pilihan mahasiswa Prodi PBA IAIN Palangka Raya, terkait $b \bar{l}$ 'ah lughawiyyah lebih banyak pada penggunaan media sosial. Hal ini menunjukan bahwa mahasiswa Prodi PBA IAIN Palangka Raya, memiliki ketertarikan di bidang teknologi dalam hal lingkungan pembelajaran bahasa. Disebutkan oleh Thu (2019), teknologi memberikan peluang besar untuk mahasiswa dalam mengeksplor lingkungan bahasa secara informal. Aktivitas yang dimulai oleh pelajar dengan lingkungan bahasa informal muncul dari kebutuhan dan minat mereka sendiri. Dalam penelitian Cole \& Vanderplank (2016) dilaporkan bahwa belajar bahasa di lingkungan informal memiliki keuntungan lebih besar karena peserta didik mengatur sendiri pembelajaran bahasa yang mereka inginkan. Peng et al. (2021) menyebutkan dalam artikelnya, bahwa menggunakan teknologi seluler untuk pembelajaran bahasa informal memiliki dampak positif, selain itu teknologi dapat mengurangi kecemasan pada peserta didik sekaligus dapat meningkatkan motivasi mereka (González-Lloret \& Ortega, 2014).

\section{Simpulan}

Dari hasil penelitian yang telah dipaparkan di atas, $b \bar{l}$ 'ah lughawiyyah era 5.0 dilihat dari aktivitas sehari-hari mahasiswa Prodi PBA IAIN Palangka Raya didominasi oleh penggunaan media sosial (Instagram, Youtube, Facebook). Selanjutnya, kegiatan perkuliahan, organisasi dan belajar mandiri. $80 \%$ pilihan pertama adalah penggunaan media sosial. Hal ini menunjukan bahwa $b \bar{\imath}$ 'ah lughawiyyah kini dapat dilakukan secara mandiri, setiap saat dan tanpa batas waktu yang ditentukan. Kebiasaan yang telah terbentuk secara tidak sengaja, seperti penggunaan sosial media yang hampir setiap saat bisa mereka lakukan tanpa batas waktu menjadikan sebuah pilihan untuk mereka menganggap hal tersebut sebagai $b \bar{\imath}$ 'ah lughawiyyah. Sumber informasi utama, yang dapat diakses secara mudah, cepat dan ringkas bukanlah lagi manusia, namun media sosial yang ada di tangan mereka. Pada dasarnya era 5.0 adalah era di mana manusia menjadikan era digital sebagai kebutuhan pokok mereka sebagai sarana kemudahan. Tidak dapat dimungkiri, sebagai manusia kita harus menjadi bagian dari perubahan tersebut. Dalam bidang pendidikan, khususnya dalam pembelajaran bahasa Arab. Oleh karena itu, menjadi penting sekali bagi para pemerhati, peneliti dan pencinta bahasa Arab itu sendiri untuk dapat menjadi bagian dari kebaharuan pembelajaran bahasa Arab, juga sebagai validator alami, agar pembelajaran bahasa Arab tetap terarah dan sampai kepada tujuannya semula. Dari penelitian yang telah kami lakukan, kami 


\section{Arabi : Journal of Arabic Studies}

merekomendasikan penelitian yang dapat dilakukan di lokasi lain terkait $b \bar{l}$ 'ah lughawiyyah era 5.0 baik dengan kajian fenomenologi, deksriptif atau studi kasus terkait pengalaman yang dirasakan.[]

\section{Daftar Rujukan}

Adi, H. M. M. 2020. "Teori Belajar Behaviorisme Albert Bandura dan Implikasinya dalam Pembelajaran Bahasa Arab", Lisanuna: Jurnal Ilmu Bahasa Arab dan Pembelajarannya, Vol. 10, No. 1.

Aflisia, N., \& Harahap, P. 2019. "Eksistensi B̋̄'ah Lughawiyah Sebagai Media Berbahasa Arab dalam Meningkatkan Kemampuan Muhādatsah Mahasiswa Prodi Pendidikan Bahasa Arab IAIN Curup", Lisanul'arab: Journal of Arabic Learning And Teaching, Vol. 8, No. 1.

Ahmadi, A., \& Ilmiani, A. M. 2020. "The Use of Teaching Media in Arabic Language Teaching During Covid-19 Pandemic", Dinamika Ilmu, Vol. 20, No. 2.

Ahmadi, F., \& Ibda, H. 2019. Konsep dan Aplikasi Literasi Baru di Era Revolusi Industri 4.0 dan Society 5.0. Donggala: Pilar Nusantara.

Akçayır, M., Dündar, H., \& Akçayır, G. 2016. "What Makes You A Digital Native? Is It Enough To Be Born After 1980?", Computers in Human Behavior, Vol. 60.

Arjunaita, A. 2020. "Pendidikan di Era Revolusi Industri 5.0", Prosiding Seminar Nasional Program Pascasarjana Universitas Pgri Palembang.

Cole, J., \& Vanderplank, R. 2016. "Comparing Autonomous and Class-Based Learners In Brazil: Evidence For The Present-Day Advantages of Informal, Out-Of-Class Learning", System, Vol. 61.

Darmawati, E. 2020. "Social Interaction \& Natural Environment Based Learning", Zirah, Vol. 1, No. 2.

Devaney, S. A. 2015. "Understanding The Millennial Generation", Journal of financial service professionals.

Fardischa, A. 2020. "Pengaruh Tontonan Berbahasa Inggris dalam Media Sosial Youtube Pada Pemerolehan Bahasa Kedua Anak Umur Tujuh Tahun", Jurnal Pena Indonesia, Vol. 6, No. 1.

González-Lloret, M., \& Ortega, L. 2014. Technology-Mediated Tblt: Researching Technology and Tasks. Amsterdam: John Benjamins Publishing Company.

Griffiths, M. D. 2019. "The Evolution Of The "Components Model of Addiction" and The Need For A Confirmatory Approach in Conceptualizing Behavioral Addictions", Düşünen Adam: The Journal of Psychiatry and Neurological Sciences, Vol. 32.

Hidayat, A. 2012. "Bī’ah Lughawiyah (Lingkungan Berbahasa) dan Pemerolehan Bahasa (Tinjauan Tentang Urgensi Lingkungan Berbahasa dalam Pemerolehan Bahasa)", An-Nida', Vol. 37, No. 1.

Ilmiani, A. M., Ahmadi, A., Rahman, N. F., \& Rahmah, Y. 2020. "Multimedia Interaktif Untuk Mengatasi Problematika Pembelajaran Bahasa Arab", Al-Ta'rib Jurnal Ilmiah Program Studi Pendidikan Bahasa Arab, Vol. 8, No. 1. 
Ilmiani, A. M., Hamidah, H., Wahdah, N., \& Mubarak, M. R. 2020. "The Implementation of Semester Learning Plan (Rps) on Mahārah Istimā' Course By Using Cartoon Story Maker", Lisania: Journal Of Arabic Education and Literature, Vol. 4, No. 1.

Ilmiani, A. M., Marsiah, M., Rahmah, Y., \& Mubarak, M. R. 2020. "Whatsapp Group to Optimize The Mahārah Istimā' Learning During The Covid-19 Pandemic", Alsinatuna, Vol. 6, No. 1.

Kamhar, M. Y., \& Lestari, E. 2019. "Pemanfaatan Sosial Media Youtube sebagai Media Pembelajaran Bahasa Indonesia di Perguruan Tinggi", Inteligensi : Jurnal Ilmu Pendidikan, Vol. 1, No. 2.

Lestiyani, P. 2020. "Analisis Persepsi Civitas Akademika terhadap Konsep Merdeka Belajar Menyongsong Era Industri 5.0", Jurnal Kependidikan: Jurnal Hasil Penelitian dan Kajian Kepustakaan di Bidang Pendidikan, Pengajaran dan Pembelajaran, Vol. 6, No. 3.

Linur, R., \& Mubarak, M. R. 2020. "Facebook Sebagai Alternatif Media Pengembangan Mahārah Kitabah", Jurnal Naskhi: Jurnal Kajian Pendidikan dan Bahasa Arab, Vol. 2, No. 1.

Liu, J., Zha, Z.-J., Tian, Q., Liu, D., Yao, T., Ling, Q., \& Mei, T. 2016. "Multi-Scale Triplet Cnn For Person Re-Identification", Proceedings of The 24th Acm International Conference on Multimedia.

Loewen, S., \& Sato, M. 2018. "Interaction and Instructed Second Language Acquisition", Language Teaching, Vol. 51, No. 3.

Maghfur, A. A., Masruhan, M., \& Indah, R. N. 2018. "Language Used in Social Media and Its Impact Toward Teens Language Acquisition", Iconquhas \& Iconist, Bandung, Indonesia.

Mao, J. 2014. "Social Media for Learning: A Mixed Methods Study on High School Students' Technology Affordances and Perspectives", Computers in Human Behavior, Vol. 33.

Moghavvemi, S., Sulaiman, A., Jaafar, N. I., \& Kasem, N. 2018. "Social Media as a Complementary Learning Tool for Teaching and Learning: The Case of Youtube", The International Journal of Management Education, Vol. 16, No. 1.

Mubarak, M. R., Wahdah, N., Ilmiani, A. M., \& Hamidah, H. 2020a. "Penggunaan Vlog dalam Pembelajaran Mahārah Kalām", Al Mi'yar: Jurnal Ilmiah Pembelajaran Bahasa Arab dan Kebahasaaraban, Vol. 3, No. 1.

Mubarak, M. R., Wahdah, N., Ilmiani, A. M., \& Hamidah, H. 2020b. "Zoom Cloud Meeting: Media Alternatif dalam Pembelajaran Maharah Kalam di Tengah Wabah Virus Corona (Covid19)", Arabiyatuna : Jurnal Bahasa Arab, Vol. 4, No. 2.

Nastiti, F. E., \& Abdu, A. R. N. 2020. "Kajian: Kesiapan Pendidikan Indonesia Menghadapi Era Society 5.0", Edcomtech Jurnal Kajian Teknologi Pendidikan, Vol. 5, No. 1.

Nufus, H. 2020. "Peranan Bi'ah Lughawaiyyah dalam Meningkatkan Kemahiran Berbahasa Arab Santri Ma'had Dar Al-Quran Tulehu Maluku Tengah", Lingue: Bahasa, Budaya, dan Sastra, Vol. 1, No. 1.

Peng, H., Jager, S., \& Lowie, W. 2021. "A Person-Centred Approach To L2 Learners' Informal Mobile Language Learning", Computer Assisted Language Learning. 
Arabi : Journal of Arabic Studies

Purba, A. 2013. "Peranan Lingkungan Bahasa dalam Pemerolehan Bahasa Kedua". Pena: Jurnal Pendidikan Bahasa dan Sastra, Vol. 2, No. 2.

Rizqi, M. R. 2017. "Resonansi Bi’ah Lughawiyyah dalam Meningkatkan Akuisisi Bahasa Arab", Dar El-Ilmi: Jurnal Studi Keagamaan, Pendidikan, dan Humaniora, Vol. 4, No. 2.

Sadat, A. 2017. "Lingkungan Bahasa Sebagai Media Pembelajaran Bahasa Arab (Ikhtiar Membangun Pembelajaran yang Efektif dan Produktif)", Al-Af'idah: Jurnal Pendidikan Bahasa Arab dan Pengajarannya, Vol. 1, No. 1.

Sa'diyah, Z. 2018. "Implementasi Pembentukan Bi'ah Lughawiyah Di Lingkungan PBA STAIN Kudus", Arabia, Vol. 10, No. 2.

Sahlström, F., Tanner, M., \& Valasmo, V. 2019. "Connected Youth, Connected Classrooms. Smartphone Use and Student and Teacher Participation During Plenary Teaching", Learning, Culture and Social Interaction, Vol. 21.

Salehudin, M. 2020. "Dampak Covid-19: Guru Mengadopsi Media Sosial Sebagai E-Learning Pada Pembelajaran Jarak Jauh", Jurnal Mudarrisuna: Media Kajian Pendidikan Agama Islam, Vol. 10, No. 1.

Salim, A. C. S. dan M. S. 2013. "Pemerolehan Bahasa Kedua Menurut Stephen Krashen", AtTa'dib, Vol. 8, No. 2.

Kolokytha, E., Loutrouki, S., Valsamidis, S., Florou, G. 2015. "Social Media Networks as a Learning Tool", Procedia Economics and Finance, Vol. 19.

Strazny, P. 2013. Encyclopedia of Linguistics. London: Routledge.

Suwandi, S. 2020. "Implementasi Pembelajaran Abad Ke-21 dan Tantangannya untuk Berperan dalam Masyarakat 5.0", Prosiding Seminar Nasional Program Pascasarjana Universitas PGRI Palembang.

Syahid, A. H. 2015. "Bahasa Arab Sebagai Bahasa Kedua (Kajian Teoretis Pemerolehan Bahasa Arab Pada Siswa Non-Native", Arabiyat: Jurnal Pendidikan Bahasa Arab dan Kebahasaaraban, Vol. 2, No. 1.

Syukriya, A. U. 2019. "Implementasi PJBL dengan Media Instagram Pada Keterampilan Menulis Bahasa Arab di SMA Islam P.B Soedirman 1 Bekasi", Prosiding Konferensi Nasional Bahasa Arab, Vol. 5, No. 5.

Taubah, M. 2017. "Menciptakan Bi'ah 'Arabiyah di Lingkungan Universitas yang Multikultural", Studi Arab, Vol. 8, No. 2.

Thu, A. S. 2019. "Autonomous Learning Materials of Structure and Written Expression for TOEFL Preparation", Lingtera, Vol. 6, No. 1.

Unsi, B. T. 2015. "Kemahiran Berbicara Bahasa Arab Melalui Penciptaan Lingkungan Bahasa", Tafáqquh: Jurnal Penelitian dan Kajian Keislaman, Vol. 3, No. 1.

Wahyuningsih, R., \& Fauzi, M. I. 2019. "Eksistensi Bī’ah Lughawiyah dalam Meningkatkan Mufradāt di Asrama Putri Ma'had Nurul Islam Tengaran", Lisanan Arabiya: Jurnal Pendidikan Bahasa Arab, Vol. 3, No. 2. 
Arabi : Journal of Arabic Studies

Weinstein, E. 2018. "The Social Media See-Saw: Positive and Negative Influences on Adolescents' Affective Well-Being", New Media \& Society, Vol. 20, No. 10.

Yanuarti, E., \& Sari, D. P. 2019. "Peran Dosen dalam Memanfaatkan Media Sosial sebagai Sarana Literasi Pembelajaran Mahasiswa", JOEAI: Journal of Education and Instruction, Vol. 2, No. 2. 